\title{
Repensar las izquierdas porque han fracasado y son necesarias. Un enfoque cristiano
}

\author{
Pedro Trigo, S. J. \\ Caracas, Venezuela
}

Es un hecho que las izquierdas han fracasado. No solo el llamado socialismo real, sino también los partidos socialdemócratas, unos y otros largo tiempo en el poder. El comunismo hizo implosión, víctima de su propia inconsistencia. El fracaso evidenció que cuando el Estado pretende sustituir a los demás agentes sociales y económicos, aunque lo haga con la mejor intención, pues piensa que las miras de estos agentes son interesadas y que solo él vela por el bien común, todo se ralentiza y empeora, y la situación se vuelve más invivible que aquella otra de evidente injusticia que pretendía revertir. Y los partidos socialdemócratas, que en la postguerra, en algunos países europeos consiguieron cierta simbiosis entre el trabajo y el capital e institucionalizaron una cierta cohesión social, logros muy apreciables, sucumbieron al consumismo y a la corrupción. Ahora se limitan a proponer y a gestionar algunas medidas compensatorias, lo cual tampoco es desdeñable, pero dejan intactos los modos y las relaciones de producción.

No podemos ocultar que la izquierda actual enfrenta un desafío muy difícil. La globalización del capital y del consumo ha tomado la delantera y ha copado todas las instancias, sobre todo, el imaginario colectivo. No pocos han comprado de modo intuitivo la pretensión, afirmada como constatación científica, de que hemos arribado al final de la historia, porque se acabaron los ensayos y ya estamos en la configuración que regirá a la humanidad de aquí en adelante. Este es el presupuesto desde el cual las agencias dan las noticias, los analistas las comentan y la mayor parte de los políticos las corrobora, incluso aquellos que proponen algunas medidas compensatorias. Ese es también el presupuesto que regula los mercados, que se tambalean cuando algo no sale según esa agenda. Por eso, los políticos de izquierda constatan que su margen de maniobra es 
muy estrecho, pues la cuota de poder que les asignan es muy exigua. Y tienen razón. Sin una capacidad de convocatoria, de compromiso y de movilización de la ciudadanía exponencialmente mayor a la que actualmente tienen, no podrán realizar verdaderas alternativas, ni siquiera podrán proponerlas.

Ahora bien, ¿no habría que afirmar también que hemos llegado a este estado de cosas porque la izquierda ha perdido hace tiempo la capacidad para imaginar alternativas, para desearlas, para trabajarlas concienzudamente y para proponerlas convincentemente? ¿Y no es cierto que han perdido esa capacidad porque como seres humanos viven en el orden establecido, tan instalados vitalmente en él como los políticos de derecha y por eso tan configurados como ellos por el imaginario vigente? Si no viven alternativamente en la actualidad, ¿cómo van a ser capaces de proponer alternativas? Las verdaderas alternativas, ¿no serían un verdadero peligro para su vida instalada? Para decirlo provocativamente, al aceptar o al menos resignarse a la configuración dada, aun en el caso de que palpen su injusticia y les duela, ¿no se han convertido en las izquierdas de la extrema derecha, de tal manera que ni siquiera llegan al centro?

De entrada, asentamos que no hay izquierda sin una propuesta de cambio en las relaciones de producción. Para nosotros, el cambio consiste en que, manteniéndose las mismas fuerzas productivas, pasen de ser antagónicas a ser simbióticas. Una izquierda resignada a las relaciones de producción impuestas por el capitalismo es, repitámoslo, la izquierda de la derecha, que no llega al centro. Esto significa que, situándonos concretamente en esta historia que nos toca vivir y en sus dinamismos, no aceptamos que el capital reduzca al trabajo a una magnitud casi residual. No, por supuesto, en su desempeño concreto, sino en los derechos, tal como ocurre en la actualidad. Tampoco tiene sentido que desaparezca la clase empresarial, tal como pretendió el marxismo. Nosotros aceptamos a ambos, porque creemos que actualmente ambos son necesarios, pero no como antagonistas, sino en una relación simbiótica, como en parte empezó a suceder en la postguerra.

En esto consiste, para nosotros, el cambio en las relaciones de producción. Se trata de pasar de la lucha de clases - sobre todo, de la lucha del capital contra el trabajo, que ha sido y es la más despiadada, y también de la lucha del trabajo contra el capital, que por lo general ha sido más razonable y ha tenido menos fuerza- a la convergencia de intereses y proyectos, y a la unidad de acción. Si ambos actores entran en este horizonte, darán el máximo y transformarán la competencia para derrotar al otro en emulación, es decir, cada uno de los agentes se esforzará por dar lo mejor de sí en la obra común con frutos compartidos.

Los obispos latinoamericanos reunidos en Medellín (1968) llamaron socialización a este proceso simultáneo y convergente, verdaderamente simbiótico, de personalización y organización, que implica la superación tanto de la dirección liberal como de la marxista. 
La socialización, entendida como proceso sociocultural de personalización y de solidaridad crecientes, nos induce a pensar que todos los sectores de la sociedad, pero en este caso, principalmente el sector económico social, deberán superar, por la justicia y la fraternidad, los antagonismos, para convertirse en agentes del desarrollo nacional y continental ${ }^{1}$.

La razón de fondo es que la contradicción antagónica deshumaniza a quien la inviste. Marx creyó evitar esta conclusión al afirmar, en contra de los métodos de lucha usuales de la izquierda radical de su tiempo, que no se trataba de combatir a las personas, sino a la clase social antagónica. Por esa razón había que cambiar los métodos. No atentados ni nada por el estilo, sino lucha estrictamente de clases, lucha dentro de los aparatos de producción. La distinción tiene sentido, pero no equivale a segmentación. Y de hecho, muchos que aceptaron el marxismo acabaron por llenarse de resentimiento e incluso de odio hacia los capitalistas, como ellos lo estaban frecuentemente de desprecio y compulsión para extraer lo máximo posible de los trabajadores. Pero además creemos que la historia ha demostrado que a todos les va mejor cuando se camina en una dirección simbiótica y se instauran unas reglas que permitan que todos ganen. De esa manera, se supera el horizonte unilateral, donde la ganancia de uno entraña la pérdida del otro ${ }^{2}$.

1. Justicia, $\mathrm{N}^{\circ}$ 13. J. Y. Calvez se refiere al "estrecho vínculo entre el respeto a la persona y la promoción de la solidaridad social" (Enseñanza social de la Iglesia, p. 57. Barcelona: Herder, 1991). En este mismo sentido, P. Bigo, un viejo tratadista de la doctrina social de la Iglesia, escribía ya en los años de 1960: "Entre la muchedumbre donde los hombres actúan como mónadas y terminan paralizando toda vida colectiva, y la totalidad donde todas las mónadas están fusionadas en una sola privándolas de toda iniciativa, no hay ningún intermediario. Pero si cada uno de los seres humanos, y cada uno de los grupos humanos que reúne a los hombres, puede al contrario referirse a la justicia y a la caridad para sus opciones, por lo tanto, puede considerar, al mismo tiempo que su bien propio, el bien común, es decir, considerar el interés general aun en contra de sus propios intereses, sin otro testigo que Dios - si en todas partes se conocen las normas que aseguran esta difícil conciliación-, entonces la muchedumbre puede formar una verdadera sociedad donde los papeles y los derechos de los individuos y los grupos armonizan en tensiones fecundas" (Doctrina social de la Iglesia, p. 259. Barcelona: Instituto Católico de Estudios Sociales, 1967).

2. Ya la Quadragesimo anno insistía en el rechazo tanto de la lucha de clases como del mercado dejado a sí mismo, desde el individualismo de los actores, y colocaba como principio rector la justicia social y la caridad social. La potencia económica, para que sea provechosa a la humanidad, debe ser "enérgicamente enfrenada y sabiamente dirigida; ahora bien, ella misma no puede enfrenarse y dirigirse. Se requieren fuerzas superiores y más nobles que tengan enérgica y prudentemente a raya a la potencia económica: la justicia y la caridad social" ( $\left.\mathrm{N}^{\circ} 88\right)$. 
No obstante, esta no será la última figura de la historia, sino que es la que nos toca vivir en la actualidad, porque, hoy por hoy, no vemos posible nada mejor. Por lo tanto, no hipostasiamos al binomio capital-trabajo, sino que decimos que, hoy por hoy, no es sustituible y que debe caminar simbióticamente y no como una entidad de fuerzas antagónicas.

Pues bien, volviendo al juicio sobre la izquierda, no podemos sostener, a estas alturas de la historia, que lo que ha fracasado sea la gestión, mientras los modelos que propuso siguen siendo válidos. Si nadie es capaz de realizarlos, es que solo eran modelos utópicos, en el mal sentido de la palabra, en cuanto que eran construcciones quiméricas, que no contenían realmente lo que proponían y prometían. Pero sacrificaban, de hecho, bienes humanos evidentes.

Pretender arribar al socialismo o al comunismo, en el sentido preciso de Marx, bien sea mediante la fase intermedia de la dictadura del proletariado, bien sea mediante la gradualidad histórica, no es deseable ni posible. Ni siquiera es un proyecto histórico, sino una vaga ensoñación, nada utópica, por cierto, en el buen sentido de esta palabra, de símbolos motivadores ${ }^{3}$. La desaparición de la

3. Nos permitimos citar en extenso a V. Havel, perseguido político del comunismo y posteriormente dos veces presidente de la República Checa: "Pienso que uno de los instrumentos más diabólicos para avasallar a unos y embelesar a otros es el singular lenguaje comunista. Es un lenguaje lleno de doblez y subterfugio, de consignas vacías y de figuras retóricas estereotipadas. Se trata de un lenguaje capaz de maravillar enormemente a las personas que no hayan descubierto su falsedad, o a las que no hayan tenido que vivir en un mundo manipulado por él. A la vez, en otras personas, ese mismo lenguaje es capaz de infundir el miedo y el terror, hasta sumirlas en un estado de perpetuo disimulo. [...]

También en mi país hubo generaciones enteras de personas que se dejaron desorientar por ese lenguaje lleno de bonitas palabras sobre la justicia, la paz y la necesidad de luchar contra los que - supuestamente al servicio de maléficas potencias extranjeras - se oponían al poder que ese lenguaje esgrime. La gran ventaja de ese lenguaje es que todas sus partes se entrelazan firmemente dentro de un sistema cerrado de dogmas que excluye todo lo que no se acomode a él. Cualquier idea un tanto original o independiente, cualquier palabra que no pertenezca al vocabulario oficial, se tilda de diversionismo ideológico, y esto, parecería, casi antes de que nadie pueda expresarla. La red de dogmas que justifican cualquier arbitrariedad del poder suele por ende adoptar la forma de una utopía, es decir, la de un concepto artificial que contiene en sí mismo todo un conjunto de razones para que todo cuanto no se avenga a su estructura tenga que ser suprimido, prohibido o destruido, en aras de un futuro feliz. [...]

Lo más cómodo es aceptar ese lenguaje, creer en él, o por lo menos, adaptarse a él. Es muy difícil mantener una óptica propia - por mucho que el sentido común nos dé mil veces la razón - siempre que eso signifique rebelarse contra el lenguaje del poder o simplemente negarse a usarlo" (Discurso pronunciado en la Universidad Internacional de la Florida, el 23 de septiembre de 2002). 
propiedad privada de los medios de producción y la marcha expedita de todo, de tal manera que los roles fijos y exigentes de la producción sean innecesarios y que permita que uno pueda dedicarse un rato a pescar y otro a otra cosa, según le apetezca $^{4}$, no puede tomarse en serio.

Nosotros sostenemos que los modelos han fracasado y que las gestiones han acabado por ser deficientes. Y que una de las causas de las deficiencias, además de la labilidad y delicuescencia humana, es el modelo mismo.

Ahora bien, es necesario reinventar los movimientos y partidos de izquierda, porque son imprescindibles. Lo son para quienes creemos que el lema de la revolución francesa, libertad, igualdad, fraternidad, es irrenunciable, si no queremos renunciar al horizonte de la calidad humana, expresado cabalmente en esa tríada indisociable. El lenguaje secular expresa la propuesta fundamental del acontecimiento cristiano.

La libertad, en la cual se afinca el liberalismo económico y político, que como neoliberalismo domina en el mundo, sobre todo, en occidente, no puede imperar sola, de modo absoluto, tal como sucede actualmente, para desgracia de la humanidad. La libertad debe estar vinculada a las otras dos magnitudes. Ante todo, tiene que equilibrarse con la lucha por la justicia, la bandera histórica de la izquierda, para lograr una cierta igualación, esto es, que la masa crítica de la sociedad se ubique en la clase media -media-media, media-baja y media-alta. De esa manera, quedará un sector minoritario de gente popular y de ricos. Pero los pobres y los muy ricos serán residuales.

Reinventar las izquierdas es todavía más necesario para los que creemos que solo la fraternidad logrará unir la libertad y la igualdad. Cuando en las sociedades no se fomenta la fraternidad, la libertad del capital acaba anulando la libertad de las personas y la igualdad, lo que actualmente sucede a nivel mundial; o la igualdad impuesta acaba con la libertad y, a la larga, también con la igualdad, tal como sucedió en el bloque comunista y todavía sucede en Cuba y en Venezuela.

4. "En todas las sociedades anteriores (el hombre ha sido) cazador, pescador, pastor o crítico, y no tiene más remedio que seguirlo siendo, si no quiere verse privado de los medios de vida; al paso que en la sociedad comunista, donde cada individuo no tiene acotado un círculo exclusivo de actividades, sino que puede desarrollar sus aptitudes en la rama que mejor le parezca, la sociedad se encarga de regular la producción general, con lo que hace cabalmente posible que yo pueda dedicarme hoy a esto y mañana a aquello, que pueda por la mañana cazar, por la tarde pescar y por la noche apacentar el ganado, y después de comer, si me place, dedicarme a criticar, sin necesidad de ser exclusivamente cazador, pescador, pastor o crítico, según los casos" (K. Marx, La ideología alemana, I-I-I-A). 
Sin el cultivo real e intenso de la fraternidad, no será posible reinventar la izquierda, de manera que cumpla su cometido de ser la alternativa superadora del totalitarismo de "mercado" que padecemos. Ponemos mercado entre comillas, porque no existe un mercado libre - aun cuando la esencia del mercado es la libertad-, sino la imposición totalitaria de las corporaciones globalizadas y, en el fondo, de los grandes financieros especulativos.

Conviene insistir en que el mercado realmente libre es, si queremos ser pesimistas, lo menos malo que los seres humanos hemos inventado para intercambiar los bienes y los servicios 5 . Todos los intentos para sustituirlo por otros agentes han empeorado la situación hasta hacerla invivible. El caso de Venezuela es paradigmático.

Ahora bien, si queremos mantenernos en el ámbito de lo realmente humano, el mercado tiene que restringirse a lo útil, sin pretender, como ocurre en la actualidad, que todo sea objeto de intercambio. No solo lo útil, sino también lo valioso, como el amor, la felicidad, la amistad, la edificación de la persona, la compañía humana, la salvación e incluso Dios. Equiparar el mercado al mundo, porque todo se reduce a bienes transables, es una aberración deshumanizadora ${ }^{6}$.

Por lo tanto, es imprescindible acertar en la crítica a la izquierda para atinar con la propuesta de una izquierda alternativa. Pero la crítica no es en sí nuestro objetivo. Sino la reconstrucción de las izquierdas y, mejor aún, su recreación. Desde ya, adelantamos que la introducción de la fraternidad como variable decisiva es la novedad imprescindible.

\section{La fraternidad no se impone por ley}

La libertad no consiste en hacer cada cual lo que buenamente quiera, sin meterse en el terreno de los demás para perjudicarlos, tal como sostiene el liberalismo. Tampoco se limita a la autodeterminación individual, tal como piensa la modernidad. La libertad humana está dirigida al bien y está modulada por el bien, pues no es otra cosa que la actuación del amor del que cada uno proviene y en el cual cada uno consiste en cuanto ser humano. Obviamente, no se trata de lo constitutivamente humano, porque todos lo somos por principio, sino de la calidad humana, distinta de las cualidades humanas que, por desgracia, pueden ser y, de hecho, llegan a ser perfectamente compatibles con la inhumanidad. La calidad humana se logra por las acciones humanizadoras, las cuales, en el fondo, son relaciones.

5. La Populorum progressio afirma que las ventajas del mercado son evidentes, "con tal de que las partes estén en condiciones iguales" ( $\left.\mathrm{N}^{\circ} 58\right)$, lo cual evidentemente no sucede hoy.

6. P. Trigo, "El mundo como mercado. Significado y juicio", en El neoliberalismo en cuestión, pp. 303-319 (Santander: Sal Terrae). 
La libertad sin amor no es libertad, sino tan solo libre albedrío, es decir, obrar con advertencia y sin coacción externa. No es libertad porque es entrega a la pasión dominante, autonomizada del resto de la persona y absolutizada, o dejación de la autonomía para dejarse modelar por lo que tiene vigencia. En el fondo, de un modo u otro, también se sucumbe a la coacción. Lo mismo podemos decir de la advertencia. A la larga, se obra sin conciencia de la realidad, para que la conciencia no remuerda, y se sustituye la realidad por el orden establecido, esto es, la realidad violentada. De esa manera, se acaba por identificar el orden establecido con la realidad, lo cual niega la posibilidad y la conveniencia de hacerle justicia, mediante la erradicación de la opresión y de la exclusión.

Del mismo modo, creemos que la igualdad impulsada por la izquierda no es, obviamente, igualación y homogeneidad. La igualdad no se da de suyo por imposición, ni a la larga. Tampoco es, como piensa la modernidad, igualdad ante la ley. La modernidad argumenta que si todos tenemos capacidad para la autodeterminación, en el fondo, todos somos iguales y en cuanto que ciudadanos, nadie puede pretender ser más que los demás por nacimiento, fortuna o poder. Sin embargo, la democracia liberal, al prescindir de las diferencias reales y al atenerse a la igualdad ante la ley, de hecho, encubre las desigualdades reales y las convalida. Por eso, en contra de lo que postula, en el liberalismo no hay ninguna igualdad ante la ley, pues esta resguarda las ventajas y las desventajas iniciales y las que sobrevienen. Así, la democracia liberal es una democracia burguesa, capitalista, aun cuando el gobierno sea conducido por socialistas. Esto será así mientras no se cambien las reglas del juego, lo cual incluye siempre la modificación de las relaciones de producción.

La igualdad a la que aspiramos es la que busca el amor ${ }^{7}$, que, por un lado, no se recarga en nadie, sino que trata de llevar su propia carga responsablemente y además busca compartir las cargas solidariamente. Esto tiene que darse en la vida cotidiana, pero también tiene que tener una expresión política, que no puede pretender abarcarlo todo, sino solo los mínimos pactados, obligatorios por ley.

No se restringe, pues, a una igualdad en principio, sancionada por las leyes, sino que se realiza en relaciones horizontales y mutuas, relaciones biófilas, en busca del bien común, desde la asunción solvente de las propias responsabili-

7. No entendemos el amor como una intensísima emoción de agrado respecto de una persona, sino como la búsqueda de su bien, pensar y hablar bien de ella, y pedir a Dios por ella. El amor no acontece "cuando las ganas se juntan", como dice la canción (Simón Díaz, Caballo Viejo), porque eso significa que cada uno satisface su propia pasión en el otro, lo cual puede acontecer sin amor: sin buscar el bien del otro, sino solo la satisfacción propia. 
dades, entendiendo que, si existe esta actitud básica, un aspecto del bien común consiste en ayudarse unos a otros a llevar las cargas ${ }^{8}$.

Actualmente, los de arriba se recargan en los de abajo, el capital en el trabajo y los grandes financistas, en último término, en los contribuyentes. Este esquema tiende a ser internalizado de tal manera, que muchos propenden a hacer con los demás como otros hacen con ellos. De este modo, la aspiración a la justicia, que provoca una cierta igualación, tiende a eclipsarse y muchos tratan de buscar ventajas privadas, en este sistema tan fuertemente asimétrico.

Esto significa que solo fomentando la fraternidad más auténtica puede llegarse al uso constructivo de la libertad y a la igualdad deseable, y obtener así la convivencia más dinámica y armónica posible y la institucionalización que la vehicule. Más concretamente, la institucionalización política que vehicule por ley los contenidos imprescindibles más básicos y que exija, de hecho, su cumplimiento con la fuerza de la ley.

El problema es que la fraternidad, a diferencia de la libertad y la igualdad, que hasta cierto punto se pueden pactar, se puede proponer, se puede practicar, se puede demostrar su conveniencia y su carácter humanizador, incluso, en cierta medida, se puede educar en ella; pero no se la puede imponer. No solamente no se la puede imponer por la fuerza, sino que no puede ser el contenido de ningún pacto que obligue por ley. Esta es la aporía de la vida política: fundamentada en la fraternidad, una actitud primordial que no es política.

Este estatuto de la política indica que se trata de una superestructura, pero en sentido distinto al que le da Marx. Es decir, desde nuestro horizonte, la política es una actividad al servicio de la familia humana y no la actividad en la que se expresa máximamente la humanidad de los seres humanos, y, por lo tanto, la que debe regirlo y modularlo todo. Este estatuto de lo político, que para nosotros no puede ser solo el reflejo de la correlación de fuerzas, ni revestir un carácter absoluto como máximo vehículo de humanización, sería el concepto en el cual tendríamos que ponernos de acuerdo.

Esto supone superar dos realidades. La primera es la que de hecho domina actualmente. La política es meramente apendicular, porque refleja la correlación de fuerzas real en una sociedad. Aceptar esta realidad implica que los seres humanos tenemos que inclinarnos y dejarnos moldear por los poderes fácticos. En nuestro caso, por el poder económico de los grandes inversores, que mediatizan la política. Pero también implica que si el proletariado y sus aliados, o,

8. Así lo afirma el Vaticano II: "El deber de justicia y caridad se cumple cada vez más contribuyendo cada uno al bien común según la propia capacidad y la necesidad ajena, promoviendo y ayudando a las instituciones, así públicas como privadas, que sirven para mejorar las condiciones de vida del hombre" (GS 30). 
en términos actuales, la aristocracia trabajadora, desde el predominio de la sociedad del conocimiento, lograra tomar el poder, tendríamos que someternos a sus dictados. La dictadura del proletariado, en nuestro caso, de los científicotécnicos, a todos los niveles.

Aceptar esta concepción de la política, tanto la neoliberal vigente como la propuesta por el marxismo, implica aceptar que no somos libres, sino que tenemos que vivir sometidos a quienes detentan el poder. Si la aceptamos, hemos renunciado a nuestra dignidad y a nuestro estatuto de personas. En este sentido, el liberalismo, al fijarse únicamente en la igualdad ante la ley, prescindiendo de la desigualdad real, de hecho, convalida la desigualdad y la custodia.

Superar la concepción de que la política debe reflejar el imperio de los poderes fácticos implica no que la política debe absolutizarse, en función de un proyecto societario de vida buena, sino que es relativa. La política no solo no es absoluta, sino que, principalmente, debe aceptar medirse siempre en el servicio concreto a la humanización de los seres humanos, lo cual debe ser comprobado en cada coyuntura.

Los revolucionarios de todos los tiempos han pensado que la política es la máxima expresión humana, porque su objetivo es procurar el bien común. También desde el cristianismo, consciente de su dimensión social y responsable, se ha tendido a pensar que la política, por ocuparse del bien común, es la máxima expresión del amor cristiano. Así lo asienta, por ejemplo, una y otra vez, el papa actual, citando a Pablo VI, aunque habría podido citar también a Pío XII, e incluso a Pío $\mathrm{XI}^{9}$, y a tratadistas de la doctrina social de la Iglesia, por ejemplo, Bigo $^{10}$, o a Juan Pablo II. El papa Francisco se pregunta: “ipuede un católico hacer política? ¡Debe! Pero, ¿puede un católico comprometerse en la política? ¡Debe! El beato Pablo VI, si no me equivoco, dijo que la política es una de las formas más altas de la caridad, porque busca el bien común"11.

¿Qué decir de esta posición que ha sido típica de las izquierdas y de cierto cristianismo comprometido con la consecución del bien común? No solo el

9. La política, en cuanto atiende al interés de la sociedad en su totalidad, constituye "el campo de la más amplia caridad, la caridad política, y por encima del cual no cabe señalar otro que el de la misma religión" (Discurso a la Federación Universitaria Católica Italiana, el 18 de diciembre de 1927).

10. "De todas las formas de la caridad, la más alta sin duda es la que no se contenta con establecer un vínculo de amor interpersonal, sino que construye una red de vínculos donde todos y cada uno puedan crecer en el amor mutuo. La 'caridad social' es esto: es el alma del cuerpo social y su principio vital: la sociedad no puede prescindir de ella" (P. Bigo, Doctrina social de la Iglesia, o. c., p. 36).

11. Diálogo espontáneo del papa con los representantes italianos de las comunidades de vida cristiana, el 30 de abril de 2015. 
cristiano, sino todo ser humano responsable, debe asumir su dimensión política y actuarla consecuentemente. Aquellos con vocación política deben ejercerla como un imperativo de humanidad y no solo como el ejercicio de una inclinación individual, y menos aún, como un empleo ventajoso.

Pero una cosa es afirmar que el ejercicio de la política es imprescindible para que una sociedad viva humanamente y que, por eso, ser político y ejercer la dimensión política es un acto de servicio muy relevante para los conciudadanos. Por lo tanto, algo relevantemente bueno. Pero otra cosa es afirmar que la política es la que vehicula la vida buena en toda su plenitud ${ }^{12}$. Esto no es así, porque los máximos de vida buena, a los cuales debemos tender irrenunciablemente, si queremos mantenernos como humanos o, mejor, si queremos humanizarnos, no pueden ser conseguidos con medios políticos. Directamente, la política solo puede pretender pactar los mínimos y velar por que se observen, estimulando su observancia, educando en esa dirección y haciendo caer, si es preciso, el peso de la ley sobre quienes no quieran observarlos. Nada menos y, directamente, nada más. Por eso, insistimos en que el estatuto de la política no es absoluto, sino relativo ${ }^{13}$.

En este sentido preciso, debe ser un ejercicio responsable. Por lo tanto, debe responder de sus decisiones ante los seres humanos, en cuanto aspiran a constituirse en seres con calidad humana. Debe responder a todos los niveles, desde la posibilidad de perder las elecciones hasta las medidas administrativas e incluso penales por sus actuaciones, dictadas por tribunales independientes.

Ahora bien, si la política acepta este carácter relativo, no puede reducirse a ser la expresión de la correlación de poderes de una sociedad. No puede resignarse a esta servidumbre, que atenta en contra de la consecución de la calidad humana. La política debe modularse por aquello que conduce comprobadamente a crear cauces que la vehiculen, para que la consecución de la calidad humana no sea una heroicidad, al tener que ir a contracorriente del orden institucional. Esto es lo fundamental, para nosotros, de una política de izquierda.

12. No podemos entender así estas palabras de Juan Pablo II, porque, aunque sea su tarea principal, ella no agota al bien común, al cual deben tender, en primer lugar, todos los ciudadanos. Por lo tanto, "El compromiso por el bien común corresponde en primer lugar a la autoridad pública, al grado que la legitimidad del Estado y su tarea principal se encuentra en alcanzar el bien común temporal" (Juan Pablo II, Discurso en la inauguración de la III Conferencia General del Episcopado Latinoamericano, el 28 de enero de 1979).

13. Este carácter relativo lo expresa el término secularidad, en contraposición a sacralidad. P. Trigo, "Secularidad, idolatría y postsecularidad en el espacio público", en J. Vitório y Á. Marin (coords.), Religião e espaco público. Cenários contemporáneos, pp. 15-67 (São Paulo: Paulinas, 2016). 


\section{2. ¿Puede la fraternidad configurar la democracia real?}

Aun cuando la política acepta no poder producir la fraternidad en la cual se fundamenta, la política de izquierda debe aceptar el aporte de los elementos pre-políticos imprescindibles, en este horizonte, orientado a consensuar y a gestionar los mínimos de vida buena pactados por la sociedad y a estimular los máximos como caldo de cultivo para que esos mínimos pactados funcionen expeditamente ${ }^{14}$.

Así, pues, si el ejercicio de la fraternidad no llega a alcanzar más consistencia que las corporaciones globalizadas y los grandes financistas, que actualmente imponen sus dictados, si ese ejercicio no produce vida y, por lo tanto, libertad, respecto a su poder avasallante, los seres humanos no tienen más remedio que plegarse a sus dictados, y lo mismo la práctica de la política.

La democracia real, en la actualidad inexistente en ningún país, solo es posible si esta relación de fraternidad, que de suyo es pre-política, alcanza un desarrollo tal que los que la ejerzan, mediante su praxis política individual e institucional, acuerpen a los políticos democráticos que logren mínimos de convivencia en justicia ${ }^{15}$. Esos mínimos deben ser pactados y expresados en la legislación y sostenidos por la institucionalidad estatal, así como también por la masa crítica de personas solidarias y sus organizaciones. Al poner al capital en su sitio, posibilitarán cierta igualdad de oportunidades, mediante la capacitación y el ejercicio de una verdadera libertad, más allá de votar en las elecciones en qué palo ahorcarse o qué consumir dentro de unas posibilidades muy limitadas y de seducciones casi irresistibles, tal como sucede en la actualidad.

Por de pronto, tenemos que admitir, como una constatación empírica, que muchas personas no están determinadas por su desventajosa situación económica, en el sentido preciso de que no responden a ella reactivamente, bien aprovechando el margen que les deje, bien resignándose a ella, bien maldiciendo de ella. Sino que responden a ella desde sí mismas, desde la capacidad de vivir y de dar vida que albergan, porque viven con libertad liberada. Así, por ejemplo,

14. Así lo afirma muy inspiradamente la Constitución pastoral sobre la Iglesia en el mundo actual, del Vaticano II: "El orden social hay que desarrollarlo a diario, fundarlo en la verdad, edificarlo sobre la justicia, vivificarlo por el amor. Pero debe encontrar en la libertad un equilibrio cada día más humano. Para cumplir todos estos objetivos hay que proceder a una renovación de los espíritus y a profundas reformas de la sociedad" (GS 26).

15. Los obispos reunidos en Medellín afirman, en el documento sobre la paz: "La justicia $\mathrm{y}$, consiguientemente, la paz se conquistan por una acción dinámica de concientización y de organización de los sectores populares, capaz de urgir a los poderes públicos, muchas veces impotentes en sus proyectos sociales sin el apoyo popular" $\left(\mathrm{N}^{\circ} 18\right)$. 
en Venezuela, donde muchos profesionales asalariados y muchos trabajadores populares se han proletarizado, no pocos de unos ni de otros, dan lo mejor de sí, aun cuando el sueldo no les alcance. Son conscientes de que su servicio es más necesario ahora que en una época de normalidad. Así, el empeño en el servicio fraterno libera su libertad para vivir en una medida considerable esas relaciones humanizadoras, a pesar de la injusticia que se les hace y del drástico deterioro de sus medios de vida. El ejercicio de la fraternidad da libertad para ir más allá de las condiciones del sistema.

El ejercicio de la fraternidad puede aplicarse a las asociaciones de vida buena y de solidaridad y de defensa de los derechos humanos, y también al ejercicio político, de tal manera que se pueda ir más allá de la seducción y la presión del sistema para modificarlo, haciéndolo más humano ${ }^{16}$.

\section{Preeminencia de la relación personal}

La preeminencia de la relación personal sobre el individualismo y el colectivismo es el presupuesto fundamental para que la humanidad sea una familia y los seres humanos nos relacionemos como hermanos. Esto es válido no solo para los cristianos, que asumimos que Jesús, al hacerse el Hijo único y eterno de Dios, nuestro hermano, nos introduce en su relación con su Padre y nos hace a todos realmente hermanos. Sino que, además, vale para todos, porque Cristo, en la pascua, derramó su Espíritu filial y fraterno sobre la humanidad entera. Por lo tanto, todos estamos capacitados para vernos como hermanos, para tratarnos como tales y para enrumbar al mundo desde esas relaciones.

El concepto de humanidad como fraternidad, más aún, como familia fundada en la hermandad, se encuentra recogido en la Declaración Universal de los Derechos Humanos, de las Naciones Unidas (1948). El primer párrafo del preámbulo se refiere a la humanidad como una sola familia: "Considerando que la libertad, la justicia y la paz en el mundo tienen por base el reconocimiento de la dignidad intrínseca y de los derechos iguales e inalienables de todos los miembros de la familia humana". Consiguientemente, en el primer artículo, pide que todos los seres humanos nos comportemos como hermanos: "Todos los seres humanos nacen libres e iguales en dignidad y derechos y, dotados como están de razón y conciencia, deben comportarse fraternalmente los unos con los otros".

El reconocimiento de la humanidad como una sola familia y, por consiguiente, el comportamiento fraterno entrañan la preeminencia de las relaciones

16. "La obra de misericordia con la que se responde aquí y ahora a una necesidad real y urgente del prójimo es, indudablemente, un acto de caridad; pero es un acto de caridad igualmente indispensable el esfuerzo dirigido a organizar y estructurar la sociedad de modo que el prójimo no tenga que padecer la miseria" (P. Bigo, Doctrina social de la Iglesia, o. c., p. 208). 
sobre la sustancia. La sustancia no es lo que tiene más realidad, tal como propaga desde su cuna griega la civilización occidental. De este principio, esta civilización deduce que cada uno se constituya a sí mismo, mediante el desarrollo de todas sus potencialidades, y salga fuera de sí para poner para sí aquello de lo que consiga apropiarse ${ }^{17}$. La Ilustración proclama que el sujeto humano se constituye por el uso de la razón analítica y crítica ${ }^{18}$. Este sujeto toma dos direcciones opuestas con niveles intermedios. La dirección vital predominante propone la expansión tendencialmente ilimitada del sujeto individual, dentro del marco establecido por la ley, que lo hace compatible con las diversas individualidades. La otra dirección vital lleva a la entrega altruista a los de abajo, para concientizarlos y promoverlos. Ambas promueven expandir al sujeto al máximo, bien sea para extenderse todo lo que pueda, ignorando los daños colaterales, bien sea para ayudar a que otros lleguen a la misma densidad humana, entendida, en este caso, como el fomento de las cualidades humanas y, más en el fondo, de la vida buena.

La segunda Ilustración toma la misma dirección. Según su planteamiento, el pueblo, por sí mismo, no puede llegar sino a las revueltas de la desesperación. Por esa razón, la conciencia del pueblo es el partido político, y lo es de un modo permanente. Es muy deseable que en el partido militen muchos del pueblo, pero ya moldeados por él. Así, son de origen popular, porque han sido reconfigurados por el partido, y militan en él, aun cuando no hayan abandonado la cotidianidad, cosa que sí hacen tendencialmente los liberados, esto es, los cuadros dirigentes. Estos viven en el partido, en la organización, entregados en cuerpo y alma a la causa popular ${ }^{19}$. Aun cuando tienen relaciones de camaradería con los miembros del partido, no mantienen relaciones propiamente personales, debido a que se mueven en el ámbito organizativo. En cuanto ilustrados, mantienen la división entre lo privado y lo público y entienden que esto último es anónimo. Por lo tanto, inhiben la suidad y se mantienen en el terreno de lo político, en el sentido más denso de la palabra: absoluto.

\section{Las insuficiencias de la izquierda}

Esta manera de entender a la izquierda muestra dos insuficiencias. Ante todo, lo estrictamente individual y las relaciones personalizadoras quedan fuera de consideración y, por lo tanto, no se les presta atención, ni son cultivadas. De esa manera, insistir en ello, mostrar su índole y su problemática, y cultivarlo sistemáticamente era tenido como una desviación pequeño-burguesa. La invocación a la moral revolucionaria no era más que retórica, en sentido estricto, ya que no

17. Según la dialéctica hegeliana, tal como aparece en sus múltiples manifestaciones escalonadas, en la Fenomenología del espíritu.

18. En esto se concreta el aude sapere, que, según Kant, es la divisa de la Ilustración.

19. Así lo sostiene el Che Guevara, en Socialismo y hombre nuevo en Cuba (Montevideo: Marcha, 1965). 
se fundamentaba en una teoría, en definitiva, en una antropología, aun cuando se hiciera con toda sinceridad y con la conciencia de que había mucho en juego.

Este vacío hizo posible que la corrupción, una posibilidad permanente, no se entendiera, ni se previniera mediante la educación y el cultivo de la interioridad y las relaciones personalizadoras, ni se procesara sistemáticamente.

La otra insuficiencia es la ausencia de relaciones horizontales y mutuas con el pueblo, porque este era considerado como el que no sabía, ni tenía, ni podía, ni valía, a pesar de que él no fuera culpable. Por eso, había que concientizarlo, organizarlo y promoverlo. Fundamentalmente, era un partícipe pasivo, aunque su actividad consistía en seguir lo más proactivamente posible las indicaciones de los ilustrados solidarios, los verdaderos sujetos. Esto se enmascaró sin más en la consideración entusiasta del pueblo, una característica latinoamericana. Se habló sinceramente de sus poderes creadores ${ }^{20}$, se asumió que "solo el pueblo salva al pueblo" ${ }^{21}$ y que "el pueblo unido jamás será vencido"22. Sin embargo, después de corear estas consignas con convencimiento, en la práctica, el pueblo era dirigido.

\section{Relaciones personalizadoras y congruencia personal}

Las relaciones personalizadoras son las que tienen más realidad, no la sustancia. Solo ellas, mantenidas desde la interioridad insobornable de cada quien, nos constituyen en personas, en cuanto distintas del individuo y del sujeto. Más en concreto, solo personalizan las relaciones horizontales, mutuas, simbióticas y basadas en la fe recíproca. Estas relaciones fraternas solo son concebibles y posibles desde la propia interioridad. Por una parte, dichas relaciones posibilitan entenderse no como un simple miembro de un conjunto, y, por otra parte, posibilitan ir más allá de dejar que la vida lo viva a uno y que cada uno saque el jugo de cada situación, desde las coordenadas dadas.

Por lo tanto, quien se entienda y asuma como individuo o como miembro de los conjuntos de los cuales forma parte no puede entenderse como persona, ni puede asumirse como tal. Dicho esto, hay que agregar que el capitalista se entiende como un individuo que juega dentro del sistema organizado, en función

20. Credo de Aquiles Nazoa.

21. La frase, que parece remontarse a Eva Duarte de Perón, fue muy usada en Venezuela por la izquierda, a finales de la década de 1960 y principios de la de 1970. Chávez la usó al asumir su última presidencia, para enfatizar que había que dar el poder al pueblo, en el sobreentendido de que el pueblo antes debía acatar las órdenes del gobierno. De esa manera, ese poder se convierte en una correa de transmisión de sus directrices.

22. La consigna formaba parte de una canción que grabó y popularizó el grupo chileno Quilapayún, en 1973, en los últimos meses de la Unidad Popular, aunque ya la había utilizado Gaitán, en un mitin, en la década de 1940. 
de expandir su capital y de sacarle el mayor partido posible, y que el camarada se entiende dentro de los lineamientos del partido y del horizonte de la revolución. En la medida en que se dejan moldear por esas coordenadas, no son personas, ya que no se relacionan en cuanto seres humanos y, por lo tanto, constituyentes de la calidad humana. En el primer caso, la relación tiene lugar por conveniencia del individuo, ya sea el contrato social o cualquier contrato privado, o bien relaciones beneficiosas o complacientes. En el segundo caso, la relación se desarrolla en cuanto miembro cualificado de los colectivos absolutizados.

Es necesario distinguir los distintos niveles de realidad y, por lo tanto, los diversos papeles de actuación. Pero distinción no equivale a separación. Todos los papeles deben ser desarrollados con congruencia personal. No es válido afirmar que uno hace lo que demanda cada papel, en cada nivel de realidad, que se autoproduce como autopoiético (N. Luhmann ${ }^{23}$ ). La separación entre lo privado y lo público, entendiendo por privado el reducto de lo individual, y lo público, aquello que posee su propia lógica, en cada nivel, ha sido llevada hasta el extremo en la hipermodernidad. Frecuentemente, esta se confunde con la postmodernidad, que postula la fragmentación. De esa manera, hay que proceder de acuerdo a la lógica de cada conjunto, sin aspirar a la congruencia entre los diversos niveles, ni a la congruencia personal.

Esta es una lógica nihilista, que postula, en definitiva, el fin de la persona como proyecto, incluso como sujeto, mientras se circunscribe a vivir como parte de conjuntos. Más aún, solo tiene en cuenta cada lance. Así, pues, no permite que ninguna presunta fidelidad al pasado, que la aspiración a alcanzar una meta y, menos aún, la combinación de ambas dimensiones, las cuales se cruzan en el presente para imprimirle dirección, lo determine. En este horizonte, la calidad humana carece de sentido. Tampoco el planteamiento de estas páginas. Ahora bien, tenemos que ser conscientes de que esta es la lógica insuflada por las corporaciones globalizadas. Ellas sí se entienden como entidades estables con planes muy precisos, porque de ese modo dominan a quienes solo existen evanescentemente.

La izquierda no puede no ser humanista, de lo contrario caerá en un "ismo". Por lo tanto, hay que afirmar que la izquierda aspira a la calidad humana, que sabe de eso y que también sabe que ella no se alcanza por medios políticos. Aunque sabe, igualmente, que la política pone unas condiciones mínimas, casi indispensables, y que, en todo caso, es un camino irrenunciable de la convivencia humanizadora.

En este sentido preciso, no estamos de acuerdo con el proclamado fin de los grandes relatos. Sí estamos de acuerdo con el fin de las utopías como

23. Sistemas sociales, pp. 54-62 (Barcelona: Anthropos, 1998). 
construcciones imaginativas, minuciosamente trazadas. Pero no estamos de acuerdo con el final de las utopías como símbolos y relatos evocadores de una plenitud humana, que no puede ser realizada completamente en la historia. En todo caso, no cabe en ninguna construcción política, fundamentada en mínimos pactados, prudentemente ampliados, y no de máximos de vida buena, los cuales no pueden ser exigidos y tampoco caben por eso en ningún pacto social ${ }^{24}$. Sin embargo, pueden ser alabados y estimulados por los representantes legítimos de la colectividad.

\section{Elementos característicos de la izquierda}

A continuación, enumeramos los elementos que debiera incluir una política de izquierdas, desde el horizonte antes delineado. Nada de esto será realidad si no se lo pone en práctica ${ }^{25}$.

- No sustituir nunca a los ciudadanos, sino potenciar su responsabilidad personal, familiar, social y política. En palabras del Vaticano II, la "responsabilidad con el hermano y con la historia". Una política de izquierdas no puede contentarse con que la ciudadanía vote, ni puede enfrentar las elecciones como una propuesta mediática.

- Tiene que ser leal en sus propuestas, es decir, estas no deben ser una simple oferta electoral, que luego no cumpla. Tiene que presentarlas a la ciudadanía para conocer su opinión y para defenderlas, aclarando y haciendo ver su sentido y su trascendencia, y, si es preciso, modificarlas.

- Tiene que mantener un diálogo constante con los ciudadanos. No para que las encuestas registren su actuación, sino para sopesar su opinión responsable. Y por eso, tiene que fomentar la opinión realmente pública, la cual no coincide, ni mucho menos, con los medios de comunicación. Tiene que retar constantemente a la ciudadanía a que participe, lo cual es distinto a un apoyo.

24. El presidente venezolano Nicolás Maduro creó el Viceministerio para la suprema felicidad social del pueblo venezolano, en octubre de 2013. La finalidad de dicha dependencia es "La Gran Misión en Amor Mayor". La "suprema felicidad" es entendida como "la visión de largo plazo que tiene como punto de partida la construcción de una estructura social incluyente, formando una nueva sociedad de incluidos, un nuevo modelo social, productivo, socialista, humanista, endógeno, donde todos vivamos en similares condiciones rumbo a lo que decía Simón Bolívar: La Suprema Felicidad Social". Estamos de acuerdo con todos los contenidos, pero estos no pueden alcanzarse políticamente. Ciertamente, la política debe establecer los mínimos, pero solo puede fomentar esos máximos de vida buena.

25. P. Trigo, “¿Cómo vivimos los venezolanos nuestra situación? Aportes para la acción social desde una perspectiva cristiana", en Horizonte para una acción social humanizadora y orgánica, pp. 84-155 (Caracas: Centro Gumilla, 2015). 
- Tiene que concebir y respetar rigurosamente la división de poderes del Estado. Los poderes judicial y electoral deben ser realmente independientes de los partidos políticos, aunque en el horizonte mencionado. Por lo tanto, se excluye el sistema de cuotas.

- Tiene que introducir, sin prisa y sin pausa, y de manera ordenada, un funcionariado basado en el concurso de méritos para que el servicio del Estado sea el mejor posible.

- Tiene que lograr la alternancia democrática y la sensibilidad alerta para detectar las artimañas de los partidos que pretendan perpetuarse en el poder, y para no creerse indispensable en el poder y, así, desviarse de su política fundamental, con tal de continuar en el gobierno. Tiene que cuidar el estatuto efectivo del Estado responsable ante la ciudadanía, incluso administrativa y penalmente.

- Tiene que normar la responsabilidad social de la empresa, lo cual incluye equilibrar el beneficio de los empleados, los proveedores y los destinatarios de la producción con el de los propietarios y los accionistas. Debe distinguir cuidadosamente la responsabilidad social de la empresa de la propaganda corporativa y vigilar por su cumplimiento ${ }^{26}$.

- Tiene que esmerarse en fomentar la propiedad cooperativa y la participación de los empleados en la gestión de la empresa privada, supuesta la debida capacitación y responsabilidad compartida, para que las decisiones no sean demagógicas, sino orientadas a la productividad y, por lo tanto, a la competitividad y a la consolidación de la producción.

- Debe vigilar constantemente, con la ayuda de las organizaciones de consumidores, de usuarios y de la sociedad civil, para que el mercado sea libre y haya una verdadera concurrencia. Es más, debe estimularla.

- Tiene que mantener la propiedad estatal de los recursos básicos, la infraestructura, la educación y la salud, y hacer compatibles estas últimas con la educación y la salud pública no-estatal y privada reglamentada.

- Tiene que impulsar decididamente la descentralización administrativa, de tal manera que lo que se pueda hacer en el nivel local no lo acapare el gobierno central. Pero esa descentralización no significa el dominio del poder local de hecho, sino el control de la ciudadanía consciente y organizada. Esto constituye el caldo de cultivo de la democracia participativa.

- Tiene que velar cuidadosamente por la preservación de la naturaleza, la propiedad común de las aguas y los montes, y la arborización de las cuencas

26. M. I. Purroy, "Ética y responsabilidad social en las empresas”, SIC, 681 (2006), 32-35. 
de los ríos. Asimismo, debe fomentar las energías renovables, como la solar y la eólica.

- Tiene que legislar e implementar la discriminación positiva del pueblo y de los sectores especialmente desfavorecidos, especialmente, los vulnerables. Pero debe hacerlo de tal manera que fomente su condición de sujetos y los ayude a desarrollar sus capacidades, sin propiciar ningún tipo de dependencia, ni de clientelismo.

- Tiene que empeñarse en un pacto social y político, en torno a los mínimos de vida buena, los cuales deben ser pactados entre todos, en la medida de lo posible. También debe hacer un esfuerzo constante para elevar prudentemente esos mínimos, pero considerando que a la política no le incumbe administrar los máximos de una vida buena, sino solo estimularlos de manera consecuente.

- Tiene que fomentar la constitución del bloque latinoamericano, teniendo presente que las elites de la cultura occidental mundializada constituyen el obstáculo principal para su constitución, dado que miran hacia Estados Unidos, la Unión Europea y cada vez más a China e India, mientras dejan de lado al continente, porque no se ven en él, y es que, en el fondo, no pertenecen a él, sino al occidente desarrollado.

- Tiene que unir al pueblo en torno a la patria grande, o, como decía Martí, a "nuestra América", sin descuidar a la elite de la cultura occidental mundializada, a la cual debe atraer.

- Tiene que impulsar una mundialización alternativa a la globalización de capitales, mercancías y turistas, que excluye a los pueblos del tercer mundo.

En conclusión, todo esto entraña un cambio en las relaciones de producción, para que estas sean progresivamente simbióticas. Lo anterior es el caldo de cultivo de esta propuesta, el único suelo donde puede nacer, practicarse y perfeccionarse. El carácter simbiótico no excluye las tensiones, ni los conflictos. Más aún, ofrece un horizonte donde estos pueden ser procesados, aunque nunca llegarán a resolverse de manera definitiva. Por eso, la política será siempre un proceso, que no puede reducirse a un esquema definitivo de relaciones de poder. La política es una manifestación del modo humano de ser, que es ser siendo, siempre perfectible y nunca perfecto. 